T.E. Balk, BPharm ${ }^{1,2}$, I.H. van der Sijs, PharmD $\mathrm{PhD}^{1}$, T. van Gelder, MD PhD ${ }^{1}$, J.J.B.

Janssen, $\mathrm{MD}^{3}$, I.M. van der Sluis, $\mathrm{MD} \mathrm{PhD}^{4}$, R.W.F. van Leeuwen, PharmD $\mathrm{PhD}^{1,3}$, F.K.

Engels, PharmD $\mathrm{PhD}^{1}$

${ }^{1}$ Department of Pharmacy Erasmus MC Rotterdam; ${ }^{2}$ Faculty of Pharmacy, Utrecht

University; ${ }^{3}$ Department of Medical Oncology Erasmus MC Cancer Institute Rotterdam;

${ }^{4}$ Department of Pediatric Hematology-Oncology Erasmus MC-Sophia Rotterdam

\title{
Contact details
}

F.K. Engels, Department of Pharmacy, Erasmus MC

Postbus 2040, 3000 CA Rotterdam

The Netherlands

E-mail: f.engels@erasmusmc.nl

Phone: 010-7033202

Counts:

- Word Count for:

- Abstract: 250 (maximum, 250)

Main Text: 2469 (excl tables, maximum 3500)

- Table Count: $4(\max 6)$

- References: 35 (max 50)

\section{A short running title (not to exceed 50 characters)}

Drug interactions in pediatric oncology patients

\section{Three to six keywords to index the content}

Drug-drug interactions, Cancer Pharmacology, Pediatric hematology/oncology,

Chemotherapy, Support care

\section{Abbreviations}

\begin{tabular}{|l|l|}
\hline DDI & Drug-drug interaction \\
\hline
\end{tabular}

This is the author manuscript accepted for publication and has undergone full peer review but has not been through the copyediting, typesetting, pagination and proofreading process, which may lead to differences between this version and the Version of Record. Please cite this article as doi:

$10.1002 / \mathrm{pbc} .26410$.

This article is protected by copyright. All rights reserved. 


\begin{tabular}{|l|l|}
\hline OTC & Over-the-counter \\
\hline MTX & Methotrexate \\
\hline ALL & Acute lymphoblastic leukemia \\
\hline
\end{tabular}

Abstract

\section{Background}

Drug-drug interactions (DDIs) can negatively affect pharmacotherapy. However pediatric DDI-studies are scarce. We undertook an exploratory study to investigate prevalence and clinical relevance of DDIs between cytostatic and non-cytostatic drugs in outpatient pediatric oncology patients.

\section{Procedure}

After informed consent and inclusion, the following information was collected: currently prescribed non-cytostatic and cytostatic drugs, comorbidities and use of over-the-counter (OTC) drugs, complementary and alternative medicines (CAM) and dietary supplements. All medication was screened for DDIs according to two databases: Micromedex ${ }^{\circledR}$ Solutions and the Dutch drug database G-Standard. The researcher presented DDIs with an associated potential for adverse outcome and a proposal for intervention to three independent experts. If the experts considered a DDI to be potentially clinically relevant and requiring intervention, the physician was notified.

Results
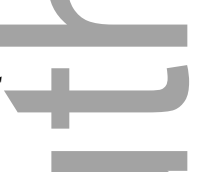

Seventy-three patients were included (median age 8.9 years). A total of 67 different DDIs were counted (66 in Micromedex ${ }^{\circledR}$ Solutions, 14 in G-standard and 13 DDIs in both databases). The medication reviews resulted in 35 interventions related to 11 different DDIs. The majority of DDIs concerned non-cytostatic drugs (25/35) and one third occurred between cytostatic and non-cytostatic drugs (10/35). The use of QTc-interval prolonging drugs 
resulted in one intervention. The use of OTC drugs, CAM or dietary supplements did not lead to DDIs.

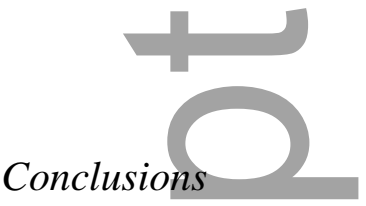

This study resulted in a selection of 11 potentially clinically relevant DDIs for 73 outpatients in our pediatric oncology department. Interventions were formulated in close collaboration between physicians and clinical pharmacists. Future research should focus on assessing DDIs concerning QTc-interval prolongation.

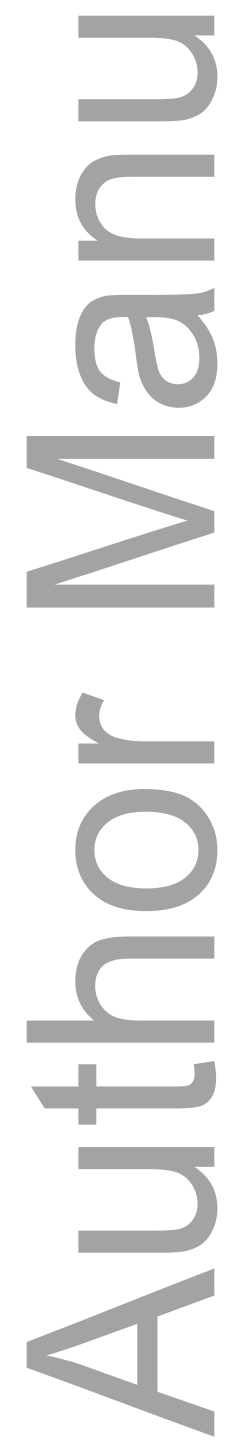




\section{Introduction}

The pharmacotherapeutic treatment of cancer patients is often associated with multiple side-

effects. In addition, a combination of drugs may result in drug-drug interactions (DDIs) which can adversely impact drug/treatment efficacy, lead to (serious) side-effects or even life-threatening events ${ }^{1}$. Of all adverse reactions related to pharmacotherapy in adults, it is estimated that $20-30 \%$ are DDIs ${ }^{1}$. Moreover, the risk of a DDI due to the concomitant use of two drugs is approximately $6 \%$ and this risk increases exponentially with the number of prescribed drugs

In our hospital, cytostatic drugs are electronically prescribed in a prescribing system different from, and not linked to the prescribing system used for non-cytostatic drugs. As a result, there is no automatic check for DDIs between these drugs and consequently no DDI alert for the prescriber. The majority of research on DDIs has been conducted in adult oncology patients ${ }^{3-}$ 8 and pediatric DDI research in this area is scarce ${ }^{9}$. It is possible that pediatric patients react differently from adults to drugs or to drug combinations which (in part) could be explained for by age-related developmental differences in body composition and organ function thus affecting drug pharmacokinetics, pharmacodynamics, or both ${ }^{10}$. We therefore undertook an exploratory, prospective study to investigate the prevalence and clinical relevance of DDIs between cytostatic and non-cytostatic drugs (including over-the-counter (OTC) drugs, complementary and alternative medicines (CAM) and dietary supplements) in outpatient pediatric oncology patients.

\section{Methods}

A prospective, observational and descriptive a study was performed during a 4 month period (November 2014 - February 2015) at the Department of Pediatric Hematology-Oncology of 
Erasmus MC-Sophia. Patients were randomly approached without regard to diagnosis, planned treatment schedule or responsible physician. After informed consent and inclusion, the following information was collected: list of currently prescribed non-cytostatic drugs (from community pharmacy \& hospital prescribing system) and prescribed cytostatic drugs for the next 3 months (from hospital oncology prescribing system). Via a structured oral interview, the medication overviews were verified and specific patient related information, such as comorbidities and use of OTC drugs, CAM and dietary supplements was obtained.

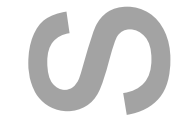

The study population consisted of outpatients younger than 18 years treated with cytostatic drugs at the pediatric oncology ward of an academic children's hospital, Erasmus MC-Sophia in Rotterdam. The outpatient setting was selected because this is a population at risk for incomplete medication overviews ${ }^{4}$, thus limiting a complete medication review by the pharmacy. Patients were included after obtaining written informed consent from both parents or guardians and also from the patient himself older than 12 years. Patients were excluded in case of insufficient knowledge of the Dutch or English language and if it was not possible to obtain a list of currently prescribed drugs or to conduct a structured oral interview.

Micromedex ${ }^{\circledR}$ Solutions and the Dutch drug database G-standard ${ }^{11,12}$ were used to screen and assess DDIs as such, making use of both an international and national database. Additional information required to optimally assess potential DDIs was extracted from the hospital information system. Per patient the DDIs, and when applicable proposed interventions, were presented to a committee of 3 independent experts (hospital pharmacist, internist-clinical pharmacologist, resident in internal medicine) by the researcher. Feedback from each expert was independently submitted back to the researcher. If there was inconsistency in the feedback the independent experts were asked to reach a consensus, upon 
which the identified DDI requiring an intervention was considered to be clinically relevant. The (hemato)oncologist in charge of the patient was advised how to manage this DDI.

\section{Results}

During the study period a total of 83 patients were randomly approached of which 73 were included $(88 \%)$. Ten patients declined participation, mostly because they already participated in other studies. All patients included were treated with a curative intent. The main patient characteristics are summarized in Table 1.

\section{Potential drug-drug interactions}

Based on Micromedex ${ }^{\circledR}$ Solutions and the G-standard database a total of 67 different DDIs were identified; 66 DDIs were documented in Micromedex ${ }^{\circledR}$ Solutions, 14 DDIs in the GStandard database and 13 DDIs were found in both databases. The DDIs of all patients summed up to a total of 432 (359 in Micromedex® Solutions, 73 in the G-standard database; Table 2), with a median of 5 DDIs per patient (range $0-28$ ). Our patients used a median of 5 drugs (range 2 - 16) concomitant to the (standard) drugs prescribed in the cytostatic treatment course and concomitant to any OTC drugs, CAM or dietary supplements. In our study $83.5 \%$ of the patients were exposed to at least one DDI. The majority of DDIs were classified in the category 'major severity' which we could attribute to the interaction between co-trimoxazole and MTX, dose unspecified. However, as discussed further on only high and intermediate dose MTX required an intervention. Of note, 84 QTc-interval prolonging interactions were counted by Micromedex ${ }^{\circledR}$ Solutions whereas the G-standard database counted none. An overview of the QTc-interval prolonging drugs prescribed in our population is shown in Table 3. 


\section{Interventions}

The medication reviews resulted in 35 interventions on 11 different DDIs (Table 4). Most interventions concerned interactions between non-cytostatic drugs (25 out of 35) and 10 interventions were related to an interaction between a cytostatic and a non-cytostatic drug. DDIs needing interventions mainly concerned the following (number of interventions in parenthesis): prophylactic oral ciprofloxacin in combination with magnesium gluconate (1), levothyroxin (1), dexamethasone (10) or prednisolone (13); MTX (high/intermediate dose) in combination with pneumocystis pneumonia prophylactic co-trimoxazole (2); vincristine in combination with itraconazole (2), voriconazole (1), aprepitant (3) or filgrastim (1) and a combination of 3 QTc-interval prolonging drugs: azithromycin, granisetron and crizotinib (1).

\section{Over-the-counter (OTC) drugs - CAM - Dietary supplements}

In our study, patients used a median of 1.9 OTC drugs (range $0-8$ ). The following OTC drugs, CAM and dietary supplements were found (number of patients in parenthesis): acetaminophen (68), multivitamins (13), vitamin D (9), melatonin (5), fishoil (2), magnesium (1), other (45). In the Netherlands the use of vitamin D supplements is advised for children under 4 years old ${ }^{14}$, which explains the majority of the users in the study population (7 out of 9 patients). No DDIs were found with OTC medication, CAM or with dietary supplements.

One patient used cannabidiol oil for pain relief and for anti-emetic reasons, However, this was not dispensed upon a prescription complying with the Dutch Opium Act, but purchased through an illegal distributor. Since 2001 the Office of Medicinal Cannabis (OMC) is the Dutch government agency responsible for the production and distribution of legal cannabis for medical purposes. There is currently one pharmacy in the Netherlands which prepares and 
dispenses medicinal cannabis oil from the medicinal cannabis of the OMC. All other cannabis, in whatever form is illegal in the Netherlands.

\section{Discussion}

To our knowledge this study is the first to assess the prevalence of clinically relevant DDIs among outpatient pediatric cancer patients in combination with specific interventions and advice on how to manage the determined DDI. The majority of DDIs concerned noncytostatic drugs (25/35) and one third occurred between cytostatic and non-cytostatic drugs (10/35). The use of OTC medication, CAM or dietary supplements was low and did not lead to DDIs. Close collaboration between physicians, clinical pharmacologists and pharmacists resulted in a well-defined selection of 11 clinically relevant DDIs. There are several reasons why we strongly advise this collaboration to be continued, also outside the setting of a clinical trial; in many hospitals there is (still) no automatic / electronic drug interaction alert between cytostatic and non-cytostatic drugs and as such prescribers must rely on DDI references and their proposed interventions which are often inconsistent. In addition, close interdisciplinary collaboration also increases the awareness for potentially clinically relevant DDIs and may help to reduce alert fatigue, an important issue in DDI clinical decision support ${ }^{15}$. We anticipate several issues which can impact on the occurrence of DDIs in pediatric oncology such as an increase in the use of tyrosine-kinase inhibitors, known to result in clinically relevant DDIs ${ }^{16}$ and more use of complementary and alternative medications (CAM), also known to be involved in PK/PD interactions with chemotherapeutics ${ }^{17}$, yet freely available via the internet and often of inferior pharmaceutical quality. The approach of our study has several strengths. There were no restrictions based on tumor type regarding inclusion of patients, which resulted in a varied, yet representative population. Furthermore, we used a national (G-standard) and an international (Micromedex ${ }^{\circledR}$ 
Solutions) DDI database, both widely used in clinical practice. A limitation of this study is that patients were not followed over time to monitor the outcome of the proposed interventions.

Several of the DDIs we found require a short discussion here. The combination of cotrimoxazole and MTX results in increased MTX toxicity involving reduced folate metabolism, synergistic nephrotoxicity and reduced MTX clearance ${ }^{18}$. Indeed, Micromedex ${ }^{\circledR}$ Solutions and G-standard both classify this DDI as 'major' and advise to avoid the combination of MTX (dose unspecified) and co-trimoxazole. This explains the high rate of major DDIs found in our study (Table 2). However, we only proposed an intervention for high dose MTX (defined as $\geq 500 \mathrm{mg} / \mathrm{m}^{2}$ ) and intermediate dose MTX (defined as 200-500 $\mathrm{mg} / \mathrm{m}^{2}$ ); co-trimoxazole was discontinued from 48 hours prior to 7 days after MTX infusion, according to the Dutch Childhood Oncology Group (DCOG) supportive care guidelines ${ }^{19}$. The majority of cases classified as 'major' DDI required no intervention as the MTX dose was low or the co-trimoxazole already discontinued. Interestingly, recent research found no evidence for an interaction between high dose MTX $\left(2,5 \mathrm{~g} / \mathrm{m}^{2}\right.$ or $\left.5 \mathrm{~g} / \mathrm{m}^{2}\right)$ and prophylactic cotrimoxazole ${ }^{20}$. Notably, Brandalise et al implemented the same precautions (leucovorin, hydratation, alkalization) for 3-weekly MTX $200 \mathrm{mg} / \mathrm{m}^{2}$ MTX as for HD-MTX ${ }^{21}$. Given the most recent data from Watts et al ${ }^{20}$ our current advice may require a revision. Ciprofloxacin is used for prophylaxis of bacterial infections during neutropenia ${ }^{19,22}$, sometimes referred to as selective decontamination of the digestive tract, SDD (although ciprofloxacin is also absorbed into the systemic circulation). Magnesium salts cause a decrease in ciprofloxacin absorption by $20 \%$ to $80 \%$ due to chelation in the gut lumen and the same occurs with calcium salts, although to a lesser extent ${ }^{23}$. An intake schedule in which ciprofloxacin is administered at least 4 hours before a magnesium salt is routinely advised ${ }^{11,23}$. Interestingly, the DCOG guidelines do not advise an interval for co-administration with 
milk products or tube feeds stating that ciprofloxacin is used prophylactically and that tube feeds are often already stopped for other, more compelling reasons making it difficult to achieve the target intake per day ${ }^{19}$. However, the most important reason is that clinical experience has demonstrated that rectal SDD swabs are negative, implying that the amount of ciprofloxacin available in the gut lumen is still sufficient despite the chelation interaction.

In adults, the use of ciprofloxacin can cause pain around an affected tendon or lead to a complete tendon rupture. Corticosteroids may potentiate this side-effect ${ }^{24}$. In our study approximately one third of the patients (23/73) were prescribed a combination of ciprofloxacin with either prednisolone or dexamethasone. Although no pediatric research has been performed and tendinopathy is mostly reported in middle-aged individuals, the DDI was reported to the responsible hemato-oncologist given the severity of the outcome ${ }^{25}$. In the case of the DDI between vincristine and azole antifungals it is advised to avoid concomitant use by stopping the azole temporarily to prevent peripheral neuropathy ${ }^{26,27}$, although there is no consensus about the length of this azole-free period ${ }^{19,28}$. This is an issue which requires further research.

The interaction between vincristine and aprepitant is based on moderate CYP3A4 inhibition by aprepitant ${ }^{29}$. Since this DDI could have severe implications the review committee advised to monitor neurotoxicity. Vincristine is associated with minimal emetic risk ${ }^{30}$ and therefore aprepitant is always initiated to mitigate the emetogenic potential of another cytostatic drug in the treatment schedule. In children already experiencing vincristine-induced neurotoxicity one could consider administering vincristine 48 hours later, thereby preventing the DDI. We anticipate an increase in pediatric aprepitant use now that the suspension has become and physicians should be aware of this DDI ${ }^{31}$.

In our study two patients who used several QTc-interval prolonging drugs ${ }^{32}$ required a more detailed review. The G-standard database advises to avoid administration of two or more 
drugs from the list 'Drugs with known Torsade de Pointes (TdP) risk' by CredibleMeds ${ }^{\circledR} 33$ and if concomitant use is unavoidable the physician should monitor the ECG ${ }^{33}$. Micromedex ${ }^{\circledR}$ Solutions gives a similar advice but does not classify QTc-interval prolonging drugs in risk categories, which explains the difference in found DDIs (84 QTc-interval prolonging DDIs in Micromedex ${ }^{\circledR}$ Solutions vs 0 in G-standard database). In the first patient 5 different QTc-interval prolonging drugs were prescribed: 2 drugs with 'Known risk of TdP', 2 with 'Possible risk of TdP' and 1 with 'Conditional risk of TdP' (Table 4). As one of the 2 'Known risk of TdP' drugs was prescribed as 'on demand', this DDI was assessed to be not clinically relevant and no intervention was proposed ${ }^{33}$. The second patient was prescribed 3 QTc-interval prolonging drugs of which 1 on the list 'Known risk of TdP' and 2 on the list 'Possible risk of TdP'. There are currently no guidelines that propose interventions upon administration of a combination of QTc-interval prolonging drugs from different lists of CredibleMeds ${ }^{\circledR}$. However, given the severity of the possible side-effect we advised to monitor the ECG in the case of 1 'Known risk of TdP' and 2 'Possible risk of TdP' drugs (excluding 'as needed' drugs). It is important to note that this intervention has not been validated and requires further research.

One intervention describes the concurrent use of vincristine and filgrastim, which has been associated with an increase in peripheral neuropathy ${ }^{34}$. A higher cumulative vincristine dose could increase the chance of neurotoxicity. Since the consequences can be serious, physicians were informed.

Research on the use of OTC drugs in the pediatric oncology population is scarce ${ }^{35}$. However, research in adults showed that $80 \%$ of the patients use OTC drugs, which in $10 \%$ of the cases results in a DDI ${ }^{4}$. In our study the use of OTC drugs, CAM and dietary supplements did not result in DDIs, possibly due to the proactive policy the physicians pursue concerning those 
drugs: patients are strongly advised not to use any medication other than the anti-cancer treatment without first consulting their physician.

In conclusion, this study gives insight in the prevalence and clinical relevance of DDIs in this specific population. Research on DDIs in the pediatric population is limited and most studies have small study populations. We strongly advise hemato-oncologists, clinical pharmacologists and pharmacists to collaborate in identifying and managing the discussed DDIs. Currently there is no clear guideline on assessing DDIs concerning multiple QTcinterval prolonging drugs. This subject should be a focus for future research.

\section{Acknowledgements}

We would like to thank all participating hemato-oncologists, research-nurses and oncology-nurses at the Erasmus MC-Sophia Children's Hospital Rotterdam.

\section{Conflict of Interest statement}

The authors declare no conflict of interest.

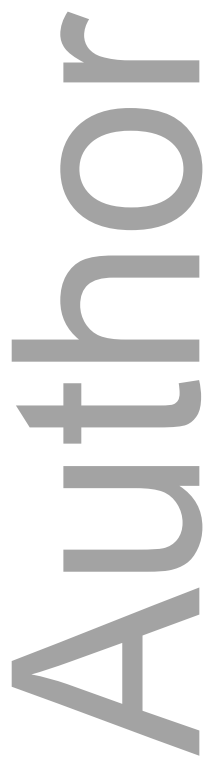




\section{References}

1. Kohler GI, Bode-Boger SM, Busse R, Hoopmann M, Welte T, Boger RH. Drug-drug interactions in medical patients: effects of in-hospital treatment and relation to multiple drug use. International journal of clinical pharmacology and therapeutics. 2000;38(11):504513.

2. Kuhlmann J, Muck W. Clinical-pharmacological strategies to assess drug interaction potential during drug development. Drug Saf. 2001;24(10):715-725.

3. Van Leeuwen RWF, Brundel DH, Neef $\mathrm{C}$, et al. Prevalence of potential drug-drug interactions in cancer patients treated with oral anticancer drugs. British journal of cancer. 2013;108(5):1071-1078.

4. Van Leeuwen RWF, Swart EL, Boven E, Boom FA, Schuitenmaker MG, Hugtenburg JG. Potential drug interactions in cancer therapy: a prevalence study using an advanced screening method. Annals of oncology : official journal of the European Society for Medical Oncology / ESMO. 2011;22(10):2334-2341.

5. Voll ML, Yap KD, Terpstra WE, Crul M. Potential drug-drug interactions between anti-cancer agents and community pharmacy dispensed drugs. Pharmacy world \& science : PWS. 2010;32(5):575-580.

6. Hadjibabaie M, Badri S, Ataei S, Moslehi AH, Karimzadeh I, Ghavamzadeh A. Potential drugdrug interactions at a referral hematology-oncology ward in Iran: a cross-sectional study. Cancer chemotherapy and pharmacology. 2013;71(6):1619-1627.

7. Riechelmann RP, Tannock IF, Wang L, Saad ED, Taback NA, Krzyzanowska MK. Potential drug interactions and duplicate prescriptions among cancer patients. J Natl Cancer Inst. 2007;99(8):592-600.

8. van Leeuwen RW, Jansman FG, van den Bemt PM, et al. Drug-drug interactions in patients treated for cancer: a prospective study on clinical interventions. Annals of oncology : official journal of the European Society for Medical Oncology / ESMO. 2015;26(5):992-997.

9. Fernandez de Palencia Espinosa MA, Diaz Carrasco MS, Fuster Soler JL, Ruiz Merino G, De la Rubia Nieto MA, Espuny Miro A. Pharmacoepidemiological study of drug-drug interactions in onco-hematological pediatric patients. International journal of clinical pharmacy. 2014;36(6):1160-1169.

10. Kearns GL, Abdel-Rahman SM, Alander SW, Blowey DL, Leeder JS, Kauffman RE. Developmental pharmacology--drug disposition, action, and therapy in infants and children. The New England journal of medicine. 2003;349(12):1157-1167.

11. Dutch Pharmacists Association (KNMP). Dutch Drug Database G-standard. https://kennisbank.knmp.nl/. Accessed 22-07-2015.

12. Truven Health. Micromedex Solutions. http://www.micromedexsolutions.com/home/dispatch/CS. Accessed 22-07-2015.

13. Hansten PDa, Horn JRa. Drug interactions analysis and management. [2009 revised edition]. ed: Vancouver.

14. Evaluation of dietary reference values for vitamin D. Health Council of the Netherlands; 2012.

http://www.gezondheidsraad.nl/sites/default/files/201215EEvaluationDietaryReferenceVita minD.pdf.

15. Payne TH, Hines LE, Chan RC, et al. Recommendations to improve the usability of drug-drug interaction clinical decision support alerts. J Am Med Inform Assoc. 2015;22(6):1243-1250.

16. Van Leeuwen RWF, Van Gelder T, Mathijssen RH, Jansman FG. Drug-drug interactions with tyrosine-kinase inhibitors: a clinical perspective. The Lancet Oncology. 2014;15(8):e315-326. 
17. Yap KY, See CS, Chan A. Clinically-relevant chemotherapy interactions with complementary and alternative medicines in patients with cancer. Recent Pat Food Nutr Agric. 2010;2(1):1255.

18. Cudmore J, Seftel M, Sisler J, Zarychanski R. Methotrexate and trimethoprimsulfamethoxazole: toxicity from this combination continues to occur. Canadian family physician Medecin de famille canadien. 2014;60(1):53-56.

19. Dutch Childhood Oncology Group (SKION). Infection prevention. 2015; https://www.skion.nl/workspace/uploads/H4-SP-Infectiepreventie-mei-2015.pdf. Accessed 12-09-2015.

20. Watts CS, Sciasci JN, Pauley JL, et al. Prophylactic Trimethoprim-Sulfamethoxazole Does Not Affect Pharmacokinetics or Pharmacodynamics of Methotrexate. Journal of pediatric hematology/oncology. 2016;38(6):449-452.

21. Brandalise SR, Pinheiro VR, Aguiar SS, et al. Benefits of the intermittent use of 6mercaptopurine and methotrexate in maintenance treatment for low-risk acute lymphoblastic leukemia in children: randomized trial from the Brazilian Childhood Cooperative Group--protocol ALL-99. Journal of clinical oncology : official journal of the American Society of Clinical Oncology. 2010;28(11):1911-1918.

22. Gafter-Gvili A, Fraser A, Paul M, et al. Antibiotic prophylaxis for bacterial infections in afebrile neutropenic patients following chemotherapy. The Cochrane database of systematic reviews. 2012;1:CD004386.

23. Baxter K, Stockley IH. Stockley's drug interactions : a source book of interactions, their mechanisms, clinical importance, and management. 8th ed. London ; Chicago:

Pharmaceutical Press; 2008.

24. Stephenson AL, Wu W, Cortes D, Rochon PA. Tendon Injury and Fluoroquinolone Use: A Systematic Review. Drug safety. 2013.

25. Mullen CA, Nair J, Sandesh S, Chan KW. Fever and neutropenia in pediatric hematopoietic stem cell transplant patients. Bone marrow transplantation. 2000;25(1):59-65.

26. Lam MSH, Ignoffo RJ. A guide to clinically relevant drug interactions in oncology. Journal of Oncology Pharmacy Practice. 2003;9(2-3):45-85.

27. Haidar C, Jeha S. Drug interactions in childhood cancer. The Lancet Oncology. 2011;12(1):9299.

28. Pana ZD, Roilides E. Risk of azole-enhanced vincristine neurotoxicity in pediatric patients with hematological malignancies: old problem - new dilemma. Pediatric blood \& cancer. 2011;57(1):30-35.

29. Aapro MS, Walko CM. Aprepitant: drug-drug interactions in perspective. Annals of oncology : official journal of the European Society for Medical Oncology / ESMO. 2010;21(12):23162323.

30. Dupuis LL, Boodhan S, Sung L, et al. Guideline for the classification of the acute emetogenic potential of antineoplastic medication in pediatric cancer patients. Pediatric blood \& cancer. 2011;57(2):191-198.

31. Kang HJ, Loftus S, Taylor A, DiCristina C, Green S, Zwaan CM. Aprepitant for the prevention of chemotherapy-induced nausea and vomiting in children: a randomised, double-blind, phase 3 trial. The Lancet Oncology. 2015;16(4):385-394.

32. Roden DM. Drug-induced prolongation of the QT interval. The New England journal of medicine. 2004;350(10):1013-1022.

33. Woosley R.L. R, K.A. Drug lists by risk groups: drugs that prolong the QT interval and/or induce Torsades de Pointes. CredibleMeds QTdrugs List;

https://www.crediblemeds.org/new-drug-list/. Accessed 22-07-2015, 2015.

This article is protected by copyright. All rights reserved. 
34. Weintraub M, Adde MA, Venzon DJ, et al. Severe atypical neuropathy associated with administration of hematopoietic colony-stimulating factors and vincristine. Journal of clinical oncology : official journal of the American Society of Clinical Oncology. 1996;14(3):935-940.

35. Magi T, Kuehni CE, Torchetti L, Wengenroth L, Luer S, Frei-Erb M. Use of Complementary and Alternative Medicine in Children with Cancer: A Study at a Swiss University Hospital. PloS one. $2015 ; 10(12): \mathrm{e} 0145787$.

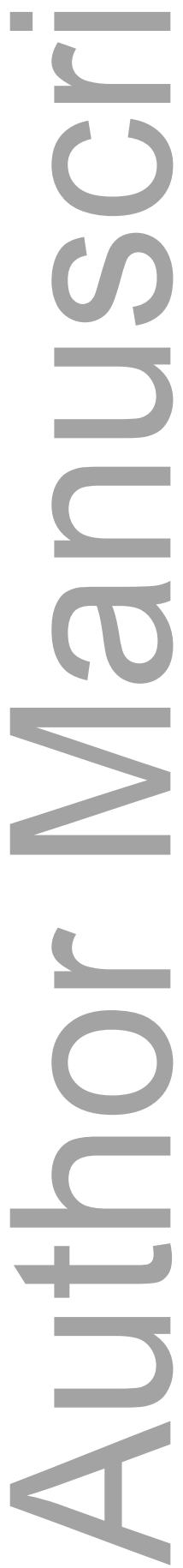


Table 1: Patient characteristics

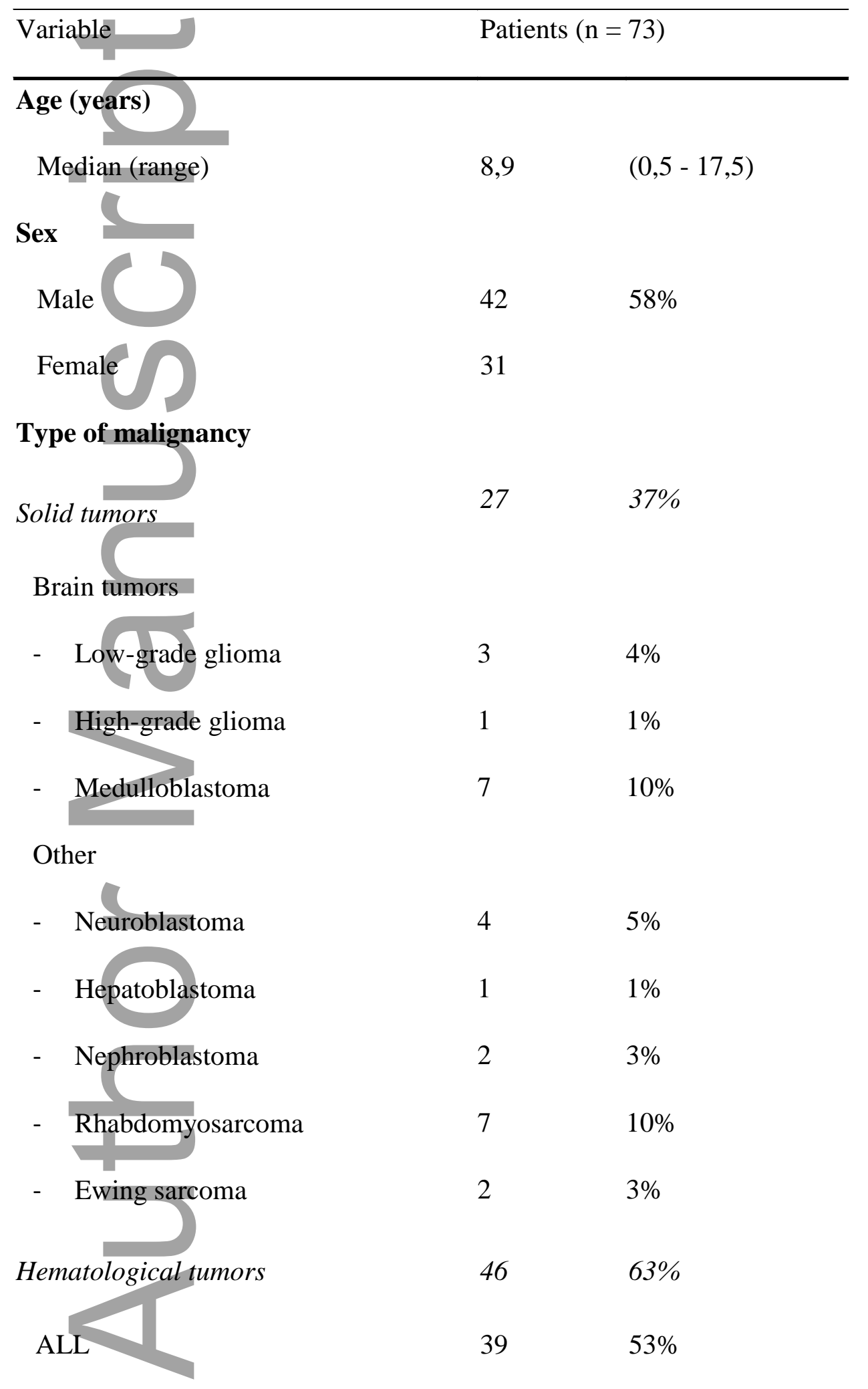


Table 2: Classification of levels of severity in Micromedex Solutions ${ }^{\circledR}$ and G-standard database

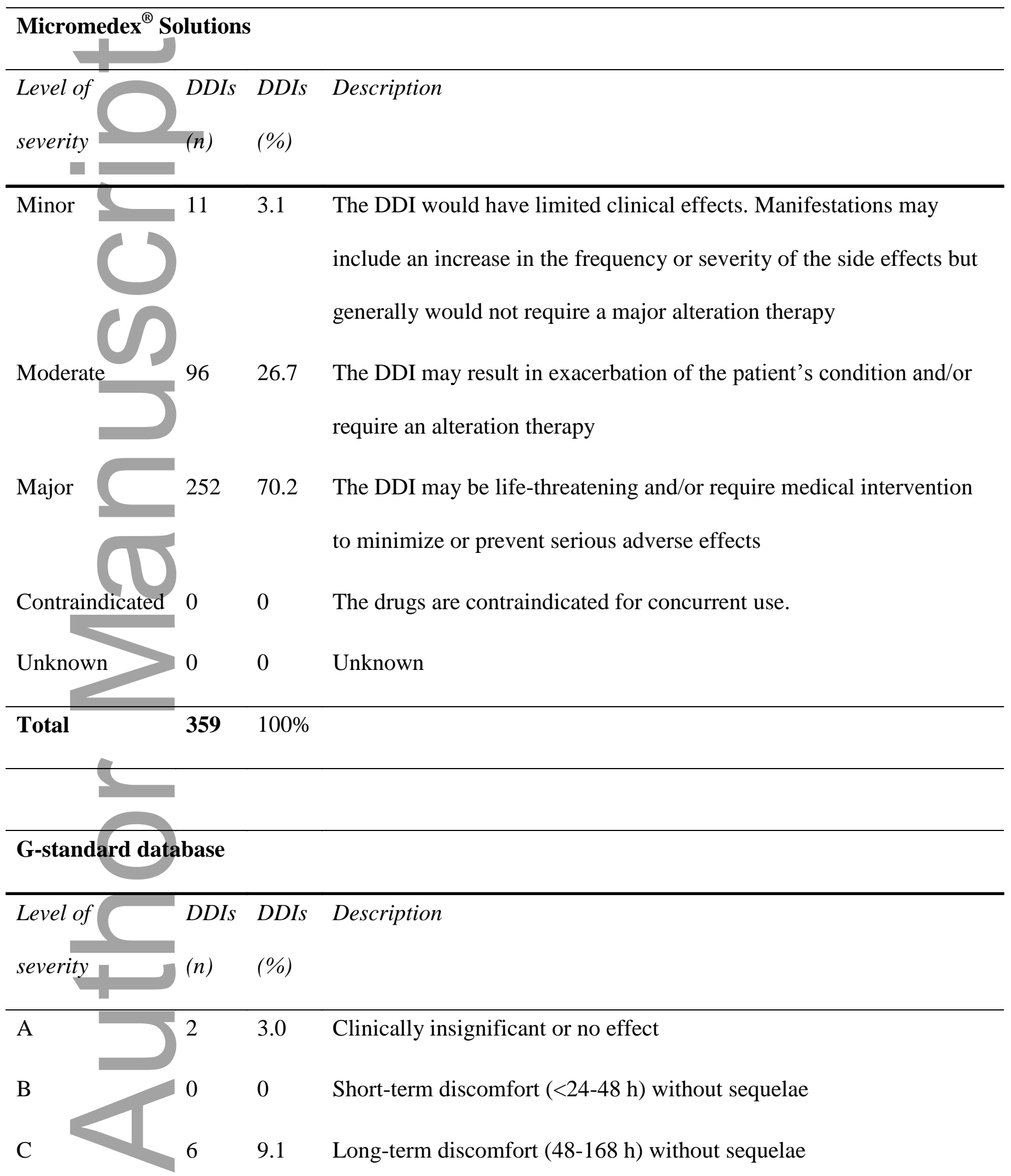

This article is protected by copyright. All rights reserved. 
Table 3: QTc-interval prolonging drugs in the studied population

\begin{tabular}{lll}
\hline Known risk & Possible risk & Conditional risk \\
\hline Azithromycin & Crizotinib & Amitryptiline \\
Ciprofloxacin & Dasatinib & Itraconazole \\
Fluconazole & Granisetron & Voriconazole \\
Ondansetron & \\
\hline Classification according to CredibleMeds ${ }^{\circledR}$ Database $^{33}$
\end{tabular}

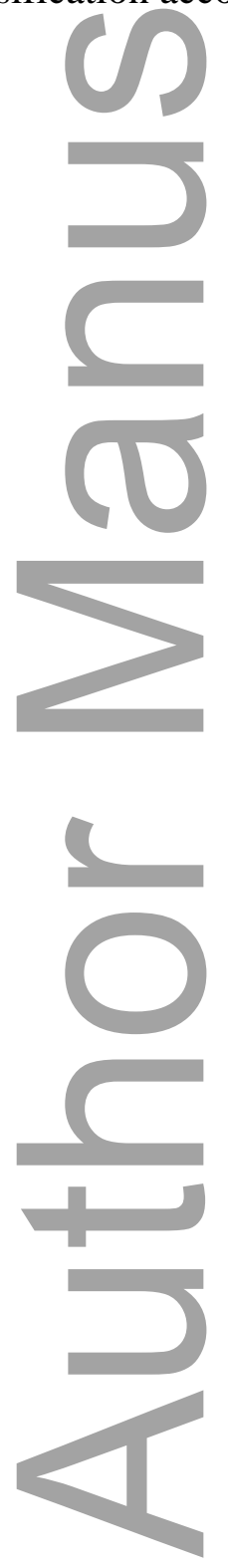

This article is protected by copyright. All rights reserved. 
Table 4: Interventions on DDIs

\begin{tabular}{|c|c|c|c|c|c|c|c|c|}
\hline $\begin{array}{l}\text { Drug } \\
\text { (victim) }\end{array}$ & Route & $\begin{array}{l}\text { Drug } \\
\text { (perpetrator) }\end{array}$ & Route & $\mathbf{N}^{a}$ & $\begin{array}{l}\mathbf{P K} / \\
\mathbf{P D}^{b}\end{array}$ & Effect DDI & Intervention & $\begin{array}{l}\text { Interventi } \\
\text { according } \\
\text { Hansten \& } \\
\text { Horn's } 13\end{array}$ \\
\hline Ciprofloxacin & p.o. & $\begin{array}{l}\text { Magnesium } \\
\text { gluconate }\end{array}$ & p.o. & 1 & PK & $\begin{array}{l}20-80 \% \\
\text { decreased } \\
\text { ciprofloxacin }\end{array}$ & $\begin{array}{l}\text { Interval } \\
\text { schedule; } \\
\text { administer } \\
\text { ciprofloxacin } \\
\text { at least } 4 \\
\text { hours before } \\
\text { magnesium }\end{array}$ & $\begin{array}{l}\text { Interval } \\
\text { schedule, } \\
\text { monitor } \\
\text { response }\end{array}$ \\
\hline Levothyroxin & p.o. & Ciprofloxacin & p.o. & 1 & PK & $\begin{array}{l}39 \% \\
\text { decreased } \\
\text { AUC of } \\
\text { levothyroxine }\end{array}$ & $\begin{array}{l}\text { Interval } \\
\text { schedule; } \\
\text { administer } \\
\text { ciprofloxacin } \\
2 \text { hours after } \\
\text { levothyroxine }\end{array}$ & $\begin{array}{l}\text { Interval } \\
\text { schedule ( } \\
\text { hours) and } \\
\text { monitor }\end{array}$ \\
\hline MTX (HD) & i.v. & Co-trimoxazole & All & 1 & PK & \multirow{2}{*}{$\begin{array}{l}\text { Increased risk } \\
\text { of MTX } \\
\text { toxicity }\end{array}$} & $\begin{array}{l}\text { Stop co- } \\
\text { trimoxazole }\end{array}$ & \multirow{2}{*}{$\begin{array}{l}\text { Choose otl } \\
\text { antibiotic } \\
\text { treatment }\end{array}$} \\
\hline $\begin{array}{l}\text { MTX } \\
\text { (interme }\end{array}$ & i.v. & Co-trimoxazole & All & 1 & PK & & $\begin{array}{l}48 \text { hours } \\
\text { before and } 7 \\
\text { days after the } \\
\text { MTX } \\
\text { infusion }\end{array}$ & \\
\hline Vincristine & i.v. & Itraconazole & All & 2 & PK & $\begin{array}{l}\text { Increased } \\
\text { vincristine } \\
\text { plasma levels } \\
\text { due to }\end{array}$ & $\begin{array}{l}\text { Vincristine } \\
\text { q3wk: stop } \\
\text { azole } 3 \text { days } \\
\text { in advance till }\end{array}$ & $\begin{array}{l}\text { Consider } \\
\text { other } \\
\text { antifungal } \\
\text { treatment }\end{array}$ \\
\hline
\end{tabular}

This article is protected by copyright. All rights reserved. 